\title{
Research on the Construction of NC Technology Course Based on OBE
}

\author{
Fan Lei, Xing Zhihui, Zhang Xiaolin \\ Shenyang Urban Construction University, ShenYang, LiaoNing Province, China \\ Shenyang Urban Construction University, ShenYang, LiaoNing Province, China \\ Shenyang Urban Construction University, ShenYang, LiaoNing Province, China
}

\begin{abstract}
This paper mainly discusses and studies the course construction of $\mathrm{NC}$ technology from the course location in the personnel training, the relationship with the orientation and training objectives of the major, the current situation of the course, and the key points and contents of the course construction.
\end{abstract}

\section{Course location in the personnel training}

This course is a professional education compulsory course for mechanical design, manufacturing and automation specialty. It is the professional knowledge that the students should master. The purpose of the course is to guide students to understand the basic process of NC machining and master the basic theoretical system, methods and application tools. The course comply with the orientation of applied engineering and technical personnel and the students' Learning process.

\section{The relationship with the professional orientation and training target}

This major aims to train applied engineering and technical personnel, so the course has the following objectives: Learn the basic theoretical knowledge of NC technology and understand the influence between $\mathrm{NC}$ technology and sustainable development; understand the composition and classification, the characteristics, the applicable scope and the development; understand the content and steps of NC programming, and be able to study engineering problems such as mechanical design, manufacturing and automation control through theoretical and technological analysis, and make research plans; understand the composition and format of the program, draw the coordinate system of the $\mathrm{NC}$ lathe, study the complex engineering problems and obtaining effective conclusions. Get skilled in function codes, analyze the solutions to complex engineering problems and seek more reasonable solutions.

\section{Course status}

\section{1 hetory course content}

Thetory course content includes: NC basic knowledge(Basic concepts, development, working process, working principle, classification, characteristics and application scope), progamming basis of $\mathrm{CNC}$ machining(Coordinate system, NC codes, NC process; $\mathrm{CNC}$ progamming (lathe, milling, $\mathrm{CNC}$ center).

\subsection{Experimental teaching content}

Since the course was set up,the theory teaching adopts multimedia combined with blackboard writing in the classroom, and the Experimental teaching adopts simulation in the computer room and the experimental teaching is simulated and verified in the computer room, and the parts are machined in the laboratory.Through the theory teaching and experimental teaching, the students can master the knowledge of the course. As a course with the strong practicality and fast updating, we should make more efforts to improve the teaching conditions, delevelop the students' comprehensive quality and ability.

\subsection{Teaching methods and conditons}

In the classroom teaching, we usually adopts the Teaching method, demonstration method, parctice method, and A certain amount of homework after class.In the experimental teaching, first the students design the drawing,second make the $\mathrm{NC}$ program, third simulate in computer, and at last machine in the $\mathrm{NC}$ lathe/milling /center machine if all the above steps are right.Through the classroom teaching and the experimental teaching, the students not only master the design, the programming, but also master the maching 
skills, and through the four steps ,deepen the understanding and mastery of NC technology. And if there is more time after class, we encourage the students self study from related books.

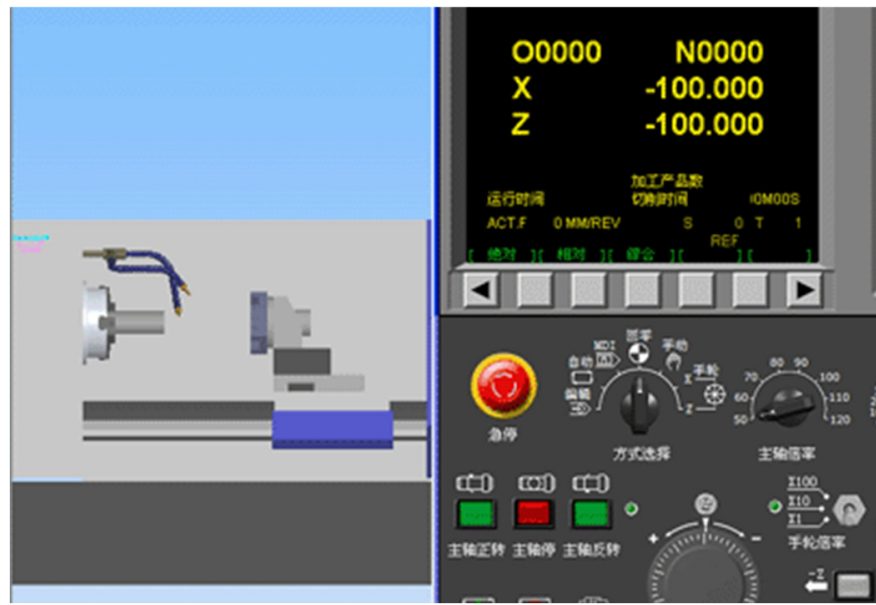

Pic 1 silulation in the software

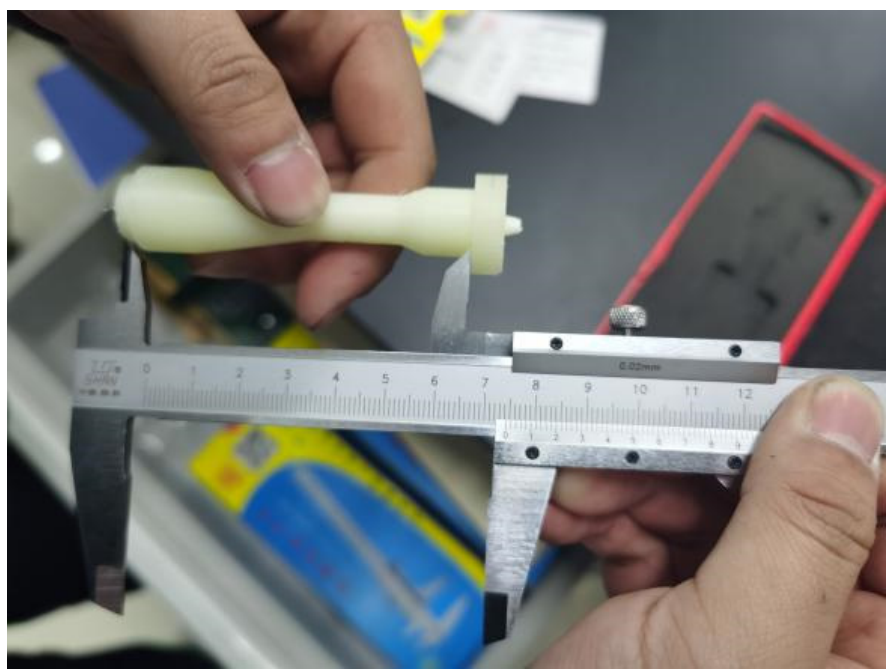

Pic 2 machining in the NC lathe

\subsection{Evaluation method}

The evaluation method widely used in the course is:usual scores+experimental scores+final exams. The final exams usually adopts the closed-book exam, and the rate is $70 \%$. But the course mainly improve the Operational capability, so the rate is high, and from the final exam ,we can't evalute the course efforts of the course, so we should have Necessary reforms.

\section{The focal points and content of the course construction}

\subsection{Course orientation}

Further clarify the course objectives, further guide students to understand the basic process of $\mathrm{NC}$ machining, and master the basic theoretical system, methods of NC technology.Have a clear career traget, especially for cultivating applied engineering and technical personnels who will engage in design and development, manufacturing, quality assurance, operation management and equipment maintenance of mechanical engineering and automation major.Course orientation reflects employment direction, which is based on improving students' ability, and conforms to students' cognitive level.

\subsection{Course design}

The course is focus on the career ability, and take career standards as the reference, and develop and design the course with the companies, all above achieve requirements of professionalism, practicality and openness.

\subsection{Construction of the teaching content}

The construction shall reflect the principle of pertinence and adaptability. According to the training objectives of the major, combined with the knowledge, ability and quality requirements for practical work tasks, the teaching contents are selected at different levels and gradients. 


\subsection{Teaching methods and conditons}

Teaching methods and conditons shall focusing on the cultivation of students' professional ability, taking the combination of work and study as the breakthrough point, according to the course content and students' characteristics, targeted teaching modes such as workstudy alternation and project-oriented are carried out, and shall complete the revision of OBE syllabus.According to the course content and the students' characteristics, case analysis, group discussion, and guidance are used flexibly to guide students to think actively and be willing to practice, thus improving learning effects. Besides multimedia, blackboard writing and laboratory equipment, the application of virtual simulation softwareshall be increased.

\subsection{Teaching effects}

Teaching effect promotes the improvement of students' comprehensive ability through the reform of academic evaluation methods. With the study of professional knowledge and skills as the core, it pays attention to the cultivation of students' professional ethics, comprehensive quality, innovative ability and practical ability while cultivating virtual simulation and practical ability. To construct an evaluation system of students' comprehensive professional quality, which combines cultural knowledge with professional practice ability, integrates theory with practice, and adapts teachers' teaching content to students' future professional post requirements. The implementation process of the reform program of academic evaluation mode is as follows:

$100 \%$ of total score $=70 \%$ of usual score $+30 \%$ of final score.

In which,

usual score $70 \%=$ class score $10 \%+$ homework $10 \%+$ experiment $50 \%$;

class score $10 \%=$ Class $\quad$ sign-in $5 \%+$ Classroom integral5\%;

Grading standard of classroom sign-in is as follows, 1 point for not arriving or being late, until the end of deduction.Classroom score standard is as follows, the full score is converted into 5 points, and the scores of students answering questions and discussions in class are subject to the statistical results of Superstar Learning Platform.

homework 10\%:

Grading standard of homework performance: the full score of each homework is converted into 10 points, and the average score of multiple homework is taken, which is subject to the statistical results of Superstar Learning Platform.

experiment $50 \%$ :

The final scores $(100 \%)$ of all experimental items are converted into $10 \%$ (rounded to the nearest whole) and included in the total scores.

Through the construction of $\mathrm{NC}$ technology course based on OBE, the students' practical ability and professional quality have been improved. At the same time, through the summary of students' classroom performance in two semesters, it is found that the quality of students' classroom teaching has been significantly improved by increasing the in-class practice assessment. In the follow-up teaching process, we should continue to carry out course construction from various aspects and angles.

In the autumn semester of 2020, the major has carried out the new academic evaluation method, which is summarized as follows: the video learning score reflects students' evaluation of basic knowledge autonomous learning ability, and the classroom score reflects students' mastery of knowledge understanding and application, mainly from the aspects of classroom selection to answer questions, classroom answering and discussion; Further evaluate students' understanding and application of knowledge through the completion of homework, the full score of the homework is 10 , with an average score of 8.53 , and accounting for $26.3 \%$ have the full scores. It shows that students have completed the basic knowledge well through homework. The practice in this course adopts the combination of Virtual Simulation Software and practical operation to cultivate students' skilled operation skills or comprehensive ability to solve technical problems. At the same time, through personalized design, students can expand and innovate their professional skills. In-class practice accounts for $50 \%$ of the total score. Students can improve their professional quality from the aspects of scheme design, simulation, operation and text combing through virtual practice in class and practical report after class. The full score of practice in class is 100 , with an average score of 74.21 , which shows that students have realized the deepening of professional courses from theoretical study to practice through virtual simulation and practice, and better combined theory with virtual practice.

\section{Conclusion}

From the construction, the students' practical ability and professional quality have been improved. At the same time, through the summary of students' classroom performance in two semesters, it is found that the quality of students' classroom teaching has been significantly improved by increasing the in-class practice assessment. In the follow-up teaching process, we should continue to carry out curriculum construction from various angles.

\section{Acknowledgments}

School-level excellent course of Shenyang Urban Construction University

\section{References}

1. Hua Ji,Yan Li,Jian Wang. (2008) A software oriented CNC system based on Linux/RTLinux.The International Journal of Advanced Manufacturing Technology,3-4.

2. Ge Yongsheng.(2020) Research on the Application of Machining Technology Based on NC Machine Tool. Internal combustion engine and 
accessories, 24:110-111.

3. Qian Yichao.(2020)Analysis of NC Machining Technology in Machining. Internal combustion engine and accessories,24:93-94.

4. $\mathrm{Xu}$ Chunying.(2020)Discussion on the Improvement Measures of New NC Machining Feed Process.Science and technology and innovation, 23:148-149.

5. Liu Jianqun.(2020)Research on Teaching Reform of Numerical Control Technology Course Based on Rain Class.China modern educational equipment,23:62-64. 